\title{
Thermodynamic Properties of Li-Sb Liquid Solution by QAM
}

\author{
S. TERLICKA, W. GĄSIOR, and A. DĘBSKI
}

The optimization of the thermodynamic properties of a liquid Li-Sb system is performed based on all available literature data. The description of the excess Gibbs energy as a function of temperature and composition is presented using a qualitative associate model (QAM), described in our earlier work on the $\mathrm{Li}-\mathrm{Pb}$ system. The modeled molar mixing enthalpy changes, excess Gibbs energy and the molar excess entropy values are characterized by strong negative deviations from the ideal solution in the entire concentration range. It was found that the best correlation between experimental data and those calculated using QAM is observed if the $\mathrm{Li}_{3} \mathrm{Sb}$ and $\mathrm{LiSb}$ associates are assumed to be in the liquid $\mathrm{Li}-\mathrm{Sb}$ solution. Calculations of the microscopic function, i.e., the concentration-concentration in the long-wavelength limit, $\left(S_{\mathrm{cc}}(0)\right)$ excess stability function (ES) and short-range-order parameter $(\operatorname{SRO}(\alpha))$ show the extreme (maximum or minimum) values almost exactly for the concentrations of $\mathrm{Li}_{3} \mathrm{Sb}$ associate (and intermetallic phase in solid alloys) and LiSb. The quotient of real $S_{\mathrm{cc}}(0)$ to this for the ideal solution $\left(S_{\mathrm{cc}}(0)_{\mathrm{id}}\right)$ is characterized by a similar property to the mentioned structure factors.

https://doi.org/10.1007/s11661-020-05898-8

(C) The Author(s) 2020

\section{INTRODUCTION}

IT is currently necessary to find an electrode material with a high reversible capacity and low overall cost of production. The $\mathrm{Li}$ and $\mathrm{Sb}$-containing alloys are of main interest because of their good energy storage properties and ability to be used in the future generation of Li-Ion or high-temperature liquid batteries, with high operational parameters. ${ }^{[1-5]}$ Preparation of such electrode materials requires information about their thermodynamic properties and phase equilibria. Thus, reliable knowledge about the thermodynamic properties of the $\mathrm{Li}-\mathrm{Sb}$ system is very important.

The thermodynamic investigation of the liquid phase existing in the $\mathrm{Li}-\mathrm{Sb}$ system was published in 2015 by Kane et al. ${ }^{[6]}$ In their paper, ${ }^{[6]}$ the activities of $\mathrm{Li}$ in $\mathrm{Li}-\mathrm{Sb}$ liquid and liquid-solid solutions were obtained by electromotive force measurements (EMF) in the temperature range from $698 \mathrm{~K}$ to $1048 \mathrm{~K}$ and concentration range of $x_{\mathrm{Li}}$ between 0.008 and 0.75 . Based on the obtained EMF results, Kane et al. ${ }^{[6]}$ calculated the partial enthalpies and entropies of $\mathrm{Li}$ in liquid $\mathrm{Li}-\mathrm{Sb}$ alloys. Then, Terlicka et al. ${ }^{[7]}$ and later Beutl et al. ${ }^{[8]}$ and $\mathrm{Li}$ et al. ${ }^{[9]}$ presented the mixing enthalpy of liquid $\mathrm{Li}-\mathrm{Sb}$

S. TERLICKA, W. GASIOR, and A. DEBSKI are with the Institute of Metallurgy and Materials Science, Polish Academy of Sciences, 25, Reymonta Street, 30-059 Kraków, Poland. Contact e-mail: s.terlicka@imim.pl

Manuscript submitted December 17, 2019.

Article published online July 6, 2020 alloys. Also, Trybula et al. ${ }^{[10]}$ investigated the thermodynamic properties of $\mathrm{Li}$-Sb liquid solutions using EMF measurements. One should also notice that the differential thermal analysis measurements conducted by Beutl et al. ${ }^{[8]}$ showed the different shape of the liquidus temperature compared to that proposed by Sangster and Pelton. ${ }^{[1]}$ Recently, the phase diagram of the $\mathrm{Li}-\mathrm{Sb}$ system was calculated in 2017 by Zhang et al. ${ }^{[12]}$ and also by $\mathrm{Li}$ et al. ${ }^{\left[{ }^{[9]}\right.}$ both using the association model.

Liquid solutions of $\mathrm{Li}-\mathrm{Sb}$ are characterized by a significant negative deviation from the ideal one. In this case, the change in the enthalpy of mixing has a minimum near the concentration corresponding to one of the intermetallic phases (compounds) in the solid state. Its shape on both sides of this concentration is similar to the linear function. A very similar situation occurs inter alia for systems such as $\mathrm{Li}-\mathrm{Bi},{ }^{[13]} \mathrm{Li}-\mathrm{Pb}^{[14-16]}$ and $\mathrm{Li}-\mathrm{Sn}{ }^{[17]}$ What is more, the partial mixing enthalpies are characterized by the S-shape (the inflection point occurs at the concentration close to that for the phase) with a very rapid increase (decrease) of the value in the vicinity of the intermetallic phase (compound). As is shown by, e.g., Saboungi et al. ${ }^{[18]}$ and Gasior et al. ${ }^{[19]}$ this shape of the partial and molar function is very difficult to describe with one of the different often used types of polynomials (models), e.g., the power series or Redlich-Kister. In such cases, as shown in Saboungi et al..$^{[18]}$ and Gasior et al., ${ }^{[19]}$ it is necessary to use two polynomials (or the graphical interpretation of experimental data): one describing a given thermodynamic function in the range of solutions 
with $\mathrm{Li}$ concentration greater than the intermetallic phase and the other for the remaining concentration range. However, in such a case it is necessary to keep the condition that derivatives calculated using both polynomials are equal at the point of inflection of a partial function. Another difficulty is that, by increasing the polynomial degree to better approximate the experimental data, the approximation function begins to wave, i.e., it has many inflection points or local minima and maxima. A completely different behavior is seen in the model (formalism) proposed in References 14 and 20 called QAM. It can describe very rapid changes of the thermodynamic isotherm, in the vicinity of the concentration characteristic of one of the intermetallic phases observed in the solid state, by using only one or two parameters calculated based on experimental data. Comparing the results of the elaboration of thermodynamics of the liquid phase by the association model, the authors of References 9 and 12 used 11 and 12 parameters for the description of thermodynamic properties of the $\mathrm{Li}_{3} \mathrm{Sb}$ associate and the excess Gibbs energy of three binary solutions, $\mathrm{Li}-\mathrm{Li}_{3} \mathrm{Sb}$, $\mathrm{Li}-\mathrm{Sb}$ and $\mathrm{Li}_{3} \mathrm{Sb}-\mathrm{Sb}$, by the Redlich-Kister model. ${ }^{[21]}$ Moreover, the reaction equilibrium constant and the additional equation have to be applied to determine the mole number of $\mathrm{Li}_{3} \mathrm{Sb}, \mathrm{Sb}$ and $\mathrm{Li}$. As can be seen, the use of the association model for the description of the composition dependence of excess Gibbs energy of binary solutions needs a large number of coefficients (11 (12) + equilibrium constant), and additionally a procedure for the determination of a number of moles based on the equation of the equilibrium constant, unless the equation for calculation of the number of moles is given (additional parameters).

Compared to the cited earlier publications ${ }^{[9,12]}$ where the association model was used, we would like to show that the interpretation of thermodynamic properties for systems with a large negative mixing enthalpy change and excess Gibbs energy is possible with a much lower number of coefficients and with acceptable standard deviation using the QAM model presented in References 14 and 20.

Therefore, the main aim of this work was to optimize the thermodynamic properties of a liquid $\mathrm{Li}-\mathrm{Sb}$ system based on all literature reports on the mixing enthalpy change and the partial excess Gibbs energy of lithium using a qualitative associate model (QAM). The correlation between experimental and calculated data for the assumed type of associates was done. Moreover, the calculation of the structure factors based on the QAM was also made and compared with the literature data.

\section{OPTIMIZATION PROCEDURE}

The qualitative associate model can be applied to determine the molar and partial mixing excess Gibbs energy for binary systems, which have strong negative deviations from the ideal solutions. In such a case, the curves describing thermodynamic functions, on both sides of the concentration characteristic for the assumed associate, have very high curvature (the radius of curvature is so large that the graph resembles almost straight lines). If the considered binary system has significant negative deviations in thermodynamic properties, the model used to develop such properties must take into account the above-mentioned linearity. The association model presented by Sommer is one such model. ${ }^{[22]}$ However, as was shown in References 9 and 12 , in this case the number of optimized thermodynamic parameters must be large and additional calculations of a number of moles of solution components have to be conducted. Thus, only the use of specialized programs will allow the determination of thermodynamic data. It is completely different for other methods where knowledge of optimized thermodynamic parameters allows calculation of the thermodynamic properties of solutions (e.g., Redlich-Kister, ${ }^{[2]]}$ power series or orthonormal polynomials models). Accepting this concept, a new approximation method was worked out ${ }^{[20]}$ and applied in our earlier paper. ${ }^{[14]}$ Because it applies only the type of associate without quantitative relations, it was named the qualitative associate model (QAM). This model can be also used to elaborate the excess Gibbs energy based on the data from the association model.

The starting point for working out this model was the observation that the description of the data discussed above is possible if the equation for the excess Gibbs energy is a modification of the following one:

$$
\begin{aligned}
\Delta G^{\mathrm{E}} & =f(T) \cdot f(X)=f(T) \cdot[M \cdot(1-X)+N \cdot X-|M \cdot(1-X)-N \cdot X|] \\
& =f(T)\left[\sqrt{M^{2}}(1-X)+\sqrt{N^{2}} X-\sqrt{(M 1-X(1-X)-N \cdot X)^{2}}\right] \\
& =f(T)\left[\left(M^{2}\right)^{0.5}(1-X)+\left(N^{2}\right)^{0.5} X-\left[(M \cdot(1-X)-N \cdot X)^{2}\right]^{0.5}\right],
\end{aligned}
$$

where $f(T)$ is the function of temperature $(T)$ defined broadly as $f(T)=a+b T+c T \ln (T)+\mathrm{d} T^{2} ; f(X)$ is the function of the composition of the solution; $(1-X)$ and $X$ are the concentration of component 1(A) and 2(B), respectively; $N$ and $M$ are integers representing the associate $\mathrm{A}_{N} \mathrm{~B}_{M}$. Except for $N$ and $M, 1-Y=N /$ $(N+M)$ and $Y=M /(N+M)$ can also be used. In the last case, they show the number of moles of components in the one mole of associate $\left(\mathrm{A}_{1-Y} \mathrm{~B}_{Y}\right)$.

The plot of the concentration function $(f(X))$ in Eq. [1] is drawn in Figure 1 for different values of $N$ and $M$ $(1-Y, Y)$ parameters. Notably, the shape of curves is very similar to the plots of the molar mixing thermodynamic functions of the systems (e.g., the enthalpy and Gibbs free energies of mixing) with large negative deviation from the ideal behavior.

If $M$ equals 2, 3 and 4 and $N$ equals 1 , the maximum of the $f(X)$ has the same value as for $N=1$ and $M=2$, 3 and 4, however, for $X$ higher than $0.5(2 / 3,3 / 4,4 / 5)$. An equation suitable for the development of experimental data cannot be obtained only by the change of the exponent in Eq. [1] from 0.5 to another one. Additionally, the concentration function $f(X)$ had to be modified. The simplest form of the equation for the description of thermodynamic properties of binary solutions with strong negative deviations and with one associate deduced by the author is as follows: 


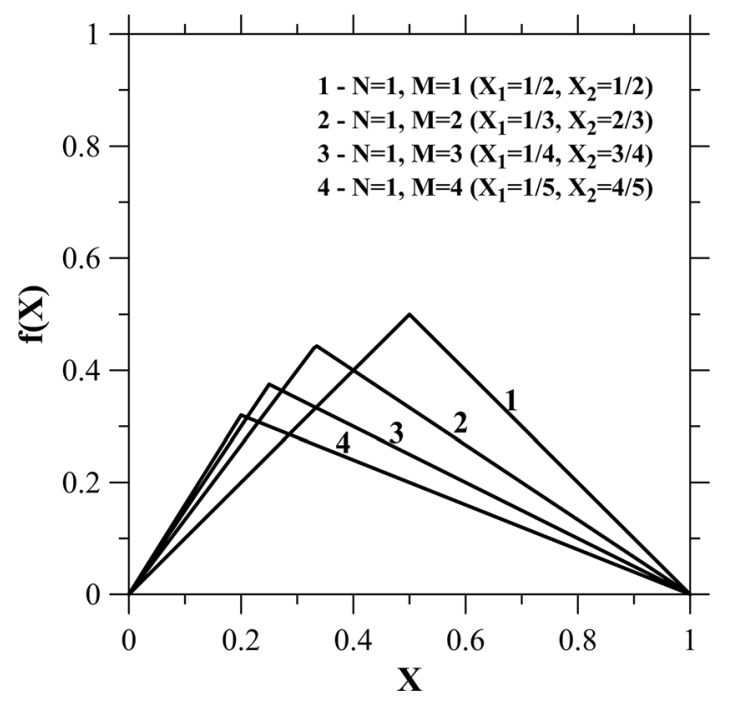

Fig. 1-Plot of the function of composition $f(X)$ of Eq. [1] $(f(T)=1)$ for various values of $N$ and $M$.

$$
\begin{aligned}
\Delta_{\text {mix }} G^{\mathrm{E}} & =f(T) f(X) \\
& =f(T) \cdot\left[F_{\mathrm{B}}^{m}(1-X)+F_{\mathrm{A}}^{m} X-F F D^{m}\right],
\end{aligned}
$$

where $F_{\mathrm{B}}=M^{2}+\Delta^{2} ; F_{\mathrm{A}}=N^{2}+\Delta^{2} ; F F D=F F^{2}+$ $\Delta^{2} ; F F=M \cdot(1-X)-N \cdot \mathrm{X} ; \Delta=1$ to $2 \cdot m ; N$ and $M$ are the stoichiometric coefficients from the associate formula $\left(\mathrm{A}_{N} \mathrm{~B}_{M}\right.$ or $\left.\mathrm{A}_{Y} \mathrm{~B}_{1-Y}, Y=M /(N+M)\right) ; 1-X$ and $X$ are the mole fraction of component $\mathrm{A}$ and $\mathrm{B} ; m$ is the parameter calculated with the use of measurement results of the given thermodynamic properties (functions); $f(T)$ is the temperature function cited earlier in this article. The dependence of the function of composition $(f(X))$ on the $m$ parameter and $X$ was also described in our previous paper ${ }^{[14]}$ (the $m$ parameter is simply an adjustable parameter that is dependent on the experimental data by the meaning of the best fit). The partial excess Gibbs energy of components can be calculated by a combination of the Gibbs-Dühem relation and Eq. [2]. The integral and partial functions may be written as follows:

$$
\begin{gathered}
\Delta_{\text {mix }} G^{\mathrm{E}}=f(T) \cdot\left[F_{\mathrm{B}}^{m}(1-X)+F_{\mathrm{A}}^{m} X-F F D^{m}\right] \\
\Delta G_{\mathrm{A}}^{\mathrm{E}}=f(T) \cdot\left\{F_{\mathrm{B}}^{m}-F F D^{m}\left[1+2 m(N+M) X \frac{F F}{F F D}\right]\right\}
\end{gathered}
$$

$$
\begin{aligned}
\Delta G_{\mathrm{B}}^{\mathrm{E}}= & f(T) \\
& \cdot\left\{F_{\mathrm{A}}^{m}-F F D^{m} \cdot\left[1-2 m(N+M)(1-X) \frac{F F}{F F D}\right]\right\} .
\end{aligned}
$$

The meaning of all symbols in Eqs. [3] through [5] has been explained above in this chapter.

If, instead of $N$ and $M$, the $1-Y$ and $Y$ coefficient of the $\mathrm{A}_{1-Y} \mathrm{~B}_{Y}$ associate are used, then $Y+(1-Y)=1$, and Eqs. [3] through [5] are transformed as follows:

$$
\begin{gathered}
\Delta_{\text {mix }} G^{\mathrm{E}}=f(T) \cdot\left[F_{\mathrm{B}}^{m}(1-X)+F_{\mathrm{A}}^{m} X-F F D^{m}\right] \\
\Delta G_{\mathrm{A}}^{\mathrm{E}}=f(T) \cdot\left\{F_{\mathrm{B}}^{m}-F F D^{m}\left[1+2 m X \frac{F F}{F F D}\right]\right\} \\
\Delta G_{\mathrm{B}}^{\mathrm{E}}=f(T) \cdot\left\{F_{\mathrm{A}}^{m}-F F D^{m} \cdot\left[1-2 m(1-X) \frac{F F}{F F D}\right]\right\},
\end{gathered}
$$

where $\quad F_{\mathrm{B}}=Y^{2}+\Delta^{2} ; \quad F_{\mathrm{A}}=(1-Y)^{2}+\Delta^{2}$; $F F D=F F^{2}+\Delta^{2} ; \quad F F=Y \cdot(1-X)-(1-Y) \cdot X ;$ $\Delta=1$ to $2 m$.

If two associates are necessary to describe the thermodynamic properties of the solution, Eqs. [2] through [8] should be a sum of two expressions representing the excess Gibbs energy of each associate.

Notably, if $m=0.5$, the function of composition $f(X)$ in Eqs. [1] and [6] has the same shape as the that in Figure 1, depending on the value of $N$ and $M$. When $N=M=1(1-Y$ and $Y=0.5)$ the maximum $f(X)$ has the value 0.5 and is equal to the maximal mole number of $A_{1} B_{1}$ associate, which can be formed in the binary A-B solution (the equilibrium reaction constant of associate formation $K_{\text {as }}$ equals infinity). For the other values of $N$ and $M$ or $1-Y$ and $Y$, the maximal values of $f(X)$ can be calculated from the equation:

$$
f_{\max }(Y)_{\infty}=2 Y(1-Y) ; \quad Y=M /(N+M)
$$

and the maximal mole number of $\mathrm{A}_{1-Y} \mathrm{~B}_{Y}$ associates equals $Y$. As a result, it changes linearly from $Y$ to 0 or from $Y$ to 1 when the composition of the solution changes from 0 to $Y$ or from $Y$ to 1 ( $X=Y$ for the $\mathrm{A}_{1-Y} \mathrm{~B}_{Y}$ associate type).

In the case of one associate, the calculations of the $a, b$ ( $c$ and $d$ if necessary) and $m$ parameter are very easy using the minimization procedures described in the next chapter. The problem is more complicated when 2 (or 3 ) associates occur, because a minimized function may possess many minima, and the obtained $a_{i}, b_{i}, c_{i}, d_{i}$ and $m_{i}(i=1,2, \ldots)$ parameters could be improper; this means, for example, that the calculated excess molar entropy may have very high positive or very low negative values.

To avoid this problem, additional observations were made. It was noticed that the smaller the negative value of the excess Gibbs energy (or the enthalpy of mixing), the more its shape is similar to that in Figure 1. This means that the lower the negative value of the thermodynamic function, the closer to 0.5 the value of $m$ should be. This fact is easy to observe when analyzing, for example, the change of the enthalpy of mixing for $\mathrm{Li}-\mathrm{Sb}$ and $\mathrm{Li}-\mathrm{Pb}^{[14]}$ systems (for $\mathrm{Li}-\mathrm{Sb}, \quad m \cong 0.5$, $\Delta_{\text {mix }} H \cong-71 \mathrm{~kJ} \mathrm{~mol}^{-1}$ and for Li-Pb, $m \cong 0.59$, $\Delta_{\text {mix }} H \cong-30 \mathrm{~kJ} \mathrm{~mol}^{-1}$ ).

The second observation concerns the difference between $m$ and 0.5 . It was noticed that

$\Delta m=m_{1}-0.5$ is close to the following:

$$
\Delta m \cong 1 / \sqrt[e]{\left|G_{1}\right|}
$$


where:

$$
G_{1}=f_{1}\left(T_{\mathrm{av}}\right)=a_{1}+b_{1} T_{\mathrm{av}}+c_{1} T_{\mathrm{av}} \ln \left(T_{\mathrm{av}}\right)+d_{1} T_{\mathrm{av}}^{2}
$$

And then:

$$
m_{1}=0.5+1 / \sqrt[e]{\left|G_{1}\right|},
$$

where $a, b, c$ and $d$ are the coefficients of temperature function $f(T)$ in Eqs. [1] through [8], $T_{\mathrm{av}}$ is the average temperature calculated using all experimental data, and $e$ is the base of the natural logarithm $(e=2,71828 \ldots) . T_{\mathrm{av}}$ is calculated just after loading all experimental data into the computer and before the optimization process (minimization of the residual sum of squares).

Parameters $m_{2}$ or $m_{3}$, characteristic for the second or third associate (if necessary), are calculated as follows:

$$
m_{2}=m_{1}+2 / \sqrt[e]{\left|G_{2}\right|} \text { and } m_{3}=m_{2}+3 / \sqrt[e]{\left|G_{3}\right|}
$$

where $G_{2(3)}$ is the value of the temperature function $f\left(T_{\text {av }}\right)$ calculated using $a_{i}, b_{i}, c_{i}, d_{i}(i=2,3)$. Using Eqs. [12] and [13] for the $m_{1(2,3)}$ calculations, and in the case of linear dependence of $f(T)$ function, the $a_{i}, b_{i}$ parameters have only one value for the given set of experimental data for which the residual sum of squares has the minimum.

\section{RESULTS AND DISCUSSION}

Using the available thermodynamic data such as the mixing enthalpy change from the solution calorimetric method $^{[7,9]}$ and the partial excess Gibbs energy of Li in $\mathrm{Li}$-Sb liquid alloys measured by the EMF study, ${ }^{[6,10]}$ the adjustable parameters $a, b$ of the $f(T)$ function in Eqs. [1] through [5] were calculated by the linear regression method, and the residual sum of squares (RSS), used as an optimal criterion, is calculated according to the following equation:

$$
\mathrm{RSS}=\sum_{i=1}^{k}\left(G_{i}^{\mathrm{cal}}-G_{i}^{\mathrm{exp}}\right)^{2}+\sum_{j=1}^{l}\left(H_{j}^{\mathrm{cal}}-H_{j}^{\mathrm{exp}}\right)^{2},
$$

where $G_{i}^{\text {cal }}$ or $H_{j}^{\text {cal }}$ and $G_{i}^{\exp }$ or $\left(H_{j}^{\text {exp }}\right)$ denote the excess Gibbs energy of $\mathrm{Li}\left(G_{\mathrm{Li}}^{\mathrm{ex}}\right)$ or mixing enthalpy change $\left(\Delta_{\text {mix }} H\right)$, calculated and experimental, respectively, and $k$ and $l$ are the number of experimental data of the cited thermodynamic functions.

The $a_{i}$ and $b_{i}$ parameters for which the residual sum of squares (RSS) has the minimum was calculated using the SIMPLEX method (computer program).

The calculations were conducted in three variants. In the first one (I), it was assumed that only the $\mathrm{Li}_{3} \mathrm{Sb}$ associate occurs in the liquid $\mathrm{Li}-\mathrm{Sb}$ solutions. In the second (II) and third (III) variants, the $\mathrm{Li}_{3} \mathrm{Sb}$ and $\mathrm{Li}_{2} \mathrm{Sb}$ and the $\mathrm{Li}_{3} \mathrm{Sb}$ and $\mathrm{LiSb}$ associates were assumed to exist in the $\mathrm{Li}-\mathrm{Sb}$ solution.

The results of calculations are presented in Table I, where the computed standard deviations for the enthalpy of mixing $\left(\mathrm{SD}_{\mathrm{H}}\right)$, partial excess Gibbs energy of $\mathrm{Li}\left(\mathrm{SD}_{\mathrm{GE}}\right)$, global one $\left(\mathrm{SD}_{\mathrm{G}}\right)$ and coefficients $a, b$ and $m$ are shown.

For the first variant, with only one associate $\left(\mathrm{Li}_{3} \mathrm{Sb}\right)$, the standard deviation was the highest. In the case of the second and third variant $\left(\mathrm{Li}_{3} \mathrm{Sb}\right.$ and $\mathrm{Li}_{2} \mathrm{Sb}, \mathrm{Li}_{3} \mathrm{Sb}$ and $\mathrm{LiSb}$ associates, respectively), all calculated standard deviations are comparable. However, because the $\mathrm{Li}_{2} \mathrm{Sb}$ intermetallic phase decomposes at about $754 \mathrm{~K}$, it was assumed that the $\mathrm{Li}_{3} \mathrm{Sb}$ and $\mathrm{LiSb}$ associates exist in the liquid phase. Thus, the results of the calculation in this study are presented for variant (III) (bold).

The integral molar mixing enthalpies and entropies, as well as excess Gibbs energy of mixing for the liquid phase calculated using the qualitative associate model for $973 \mathrm{~K}$, are collected in Table II and are presented in Figures 2 through 4 . Moreover, the partial quantities of $\mathrm{Li}$ and $\mathrm{Sb}$ components for the liquid phase existing in the Li-Sb system estimated in this study are listed in Tables III and IV, respectively. Furthermore, Figures 2 and 3 show the comparison between values elaborated using the QAM model and obtained experimentally by References 6, 7, 9, and 10. The calculated standard deviation for the mixing enthalpy change equals $577 \mathrm{~J} \cdot \mathrm{mol}^{-1}$ and for the partial excess Gibbs energy of Li $2002 \mathrm{~J} \cdot \mathrm{mol}^{-1}$ and global one reaches $1514 \mathrm{~J} \cdot \mathrm{mol}^{-1}$.

The molar $\Delta_{\text {mix }} H, \Delta_{\text {mix }} S^{\mathrm{E}}$ and $\Delta_{\text {mix }} G^{\mathrm{E}}$ obtained from calculations are characterized by a reasonable negative deviation from the ideal solution, which can be seen in Figures 2 through 4 . The largest difference between counted and experimental results, in the case of integral molar mixing enthalpy changes, is observed for $x_{\mathrm{Li}}=0.5397$ and is about $1812 \mathrm{~J} \mathrm{~mol}^{-1}$. Minimal value of the molar $\Delta_{\text {mix }} G^{\mathrm{E}}$ calculated for $973 \mathrm{~K}$ occurs for the composition $x_{\mathrm{Li}}=0.73$ and equals $-52221 \mathrm{~J} \mathrm{~mol}^{-1}$. The molar $\Delta_{\text {mix }} H$ and $\Delta_{\text {mix }} S^{\mathrm{E}}$ have minimal values for $x_{\mathrm{Li}}=0.74$, which are $-74,900 \mathrm{~J} \mathrm{~mol}^{-1}$ and - 23.378 J (mol K) $)^{-1}$, respectively.

All presented molar thermodynamic functions have an almost triangle shape (which means that the radius of curvature is so large that the graph resembles almost straight lines and the equilibrium reaction constant of associate formation $K_{\text {as }}$ equals infinity). This means that the partial ones must be of S-shape with the inflection point for $x_{\mathrm{Li}}=0.75\left(\mathrm{Li}_{3} \mathrm{Sb}\right)$, which is confirmed in Figures 2 through 4. Presented in Figure 2, the calculated $\Delta G_{\mathrm{Li}}^{\mathrm{E}}$ data and experimental values ${ }^{[6,10]}$ are generally in good agreement, and the observed deviation are $<6$ pet.

The $\Delta G_{\mathrm{Li}}^{\mathrm{E}}$ and $\Delta G_{\mathrm{Sb}}^{\mathrm{E}}$ at 973 are negative in the entire concentration range, and their minimal values are -79947 and $-222,595 \mathrm{~J} \mathrm{~mol}^{-1}$, respectively, in contrast to the partial mixing enthalpy change and partial excess entropy of $\mathrm{Li}$ and $\mathrm{Sb}$, which are characterized by both negative and positive values. Such behavior of the mentioned partial functions is the effect of the slightly convex nature of the change of enthalpy of mixing $\Delta_{\text {mix }} H$ for the alloys of compositions $<x_{\mathrm{Li}}=0.55$. The limiting values of partial enthalpy and the partial excess entropy of $\mathrm{Li}$ at $973 \mathrm{~K}$ are $-86,599 \mathrm{~J} \mathrm{~mol}^{-1}$ and $-6.84 \mathrm{~J}(\mathrm{~mol} \mathrm{~K})^{-1}$, respectively. The same functions for antimony reach $-318657 \mathrm{~J} \mathrm{~mol}^{-1}$ and 
Table I. Standard Deviations Obtained for the Different Associates that are Assumed to Exist in Liquid Li-Sb Alloys

\begin{tabular}{llcccrrr}
\hline & & & & \multicolumn{2}{c}{ Parameters } \\
\cline { 3 - 7 } Variant & Associates & $\mathrm{SD}_{\mathrm{H}}\left(\mathbf{J ~ m o l}^{-1}\right)$ & $\mathrm{SD}_{\mathrm{GE}}\left(\mathbf{J ~ m o l}^{-1}\right)$ & $\mathrm{SD}_{\mathrm{G}}\left(\mathbf{J ~ m o l}^{-1}\right)$ & $a\left(\mathrm{~J} \mathrm{~mol}^{-1}\right)$ & $b\left(\mathrm{~J}\left(\mathrm{~mol} \mathrm{~K}^{-1}\right)\right.$ & $m$ \\
\hline $\mathrm{I}$ & $\mathrm{Li}_{3} \mathrm{Sb}$ & 2233 & 2121 & 2174 & $-192,117.85$ & 40.5118 & 0.5124 \\
II & $\mathrm{Li}_{3} \mathrm{Sb}, \mathrm{Li}_{2} \mathrm{Sb}$ & 584 & 2000 & 1514 & $-268,008.57$ & 129.0726 & 0.5126 \\
III & $\mathbf{L i}_{3} \mathbf{S b}, \mathbf{L i S b}$ & $\mathbf{5 7 7}$ & $\mathbf{2 0 0 2}$ & $\mathbf{1 5 1 4}$ & $-\mathbf{2 3 8 , 5 3 7 . 5 8}$ & $\mathbf{9 4 . 4 5 5 8}$ & $\mathbf{0 . 5 1 2 5}$ \\
\hline
\end{tabular}

Table II. Integral Quantities of the Liquid Phase at $T=973 \mathrm{~K}$

\begin{tabular}{lcccc}
\hline$x_{\mathrm{Sb}}$ & $\Delta_{\text {mix }} G^{\mathrm{E}}\left(\mathrm{J} \mathrm{mol}^{-1}\right)$ & $\Delta_{\text {mix }} H\left(\mathrm{~J} \mathrm{~mol}^{-1}\right)$ & $\Delta_{\text {mix }} S^{\mathrm{E}}\left(\mathrm{J}(\mathrm{mol} \mathrm{K})^{-1}\right)$ & $S_{\mathrm{cc}}(0)$ at $1500 \mathrm{~K}$ \\
\hline 0 & 0 & 0 & 0 & 0 \\
0.1 & -22113 & -31793 & -9.95 & 0.064 \\
0.2 & -43510 & -62834 & -21.55 & 0.026 \\
0.3 & -51202 & -72171 & -15.34 & 0.026 \\
0.4 & -45154 & -60081 & -10.05 & 0.073 \\
0.5 & -38290 & -48067 & -6.25 & 0.073 \\
0.6 & -31036 & -37114 & -3.71 & 0.103 \\
0.7 & -23511 & -27124 & -2.01 & 0.106 \\
0.8 & -15798 & -17751 & -0.83 & 0.075 \\
0.9 & -7950 & -8754 & 0 & 0 \\
1 & 0 & 0 & 0 & \\
\hline
\end{tabular}

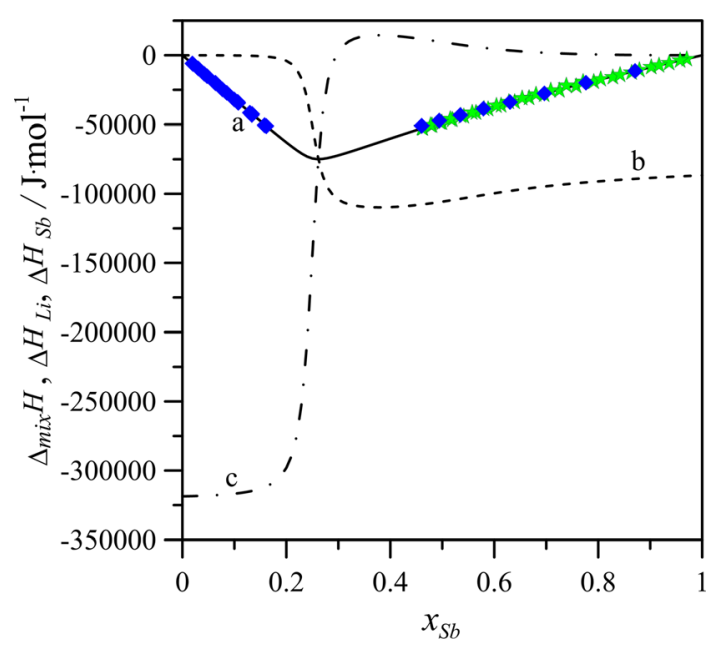

Fig. 2-Molar $\Delta_{m i x} H$ (a) and partial enthalpy $\left\{\Delta H_{\mathrm{Li}}\right.$ (b), $\Delta H_{\mathrm{Sb}}$ (c) $\}$ of Li-Sb solutions at $T=973 \mathrm{~K}$. Points ${ }^{[7]}$ at $T=1024 \mathrm{~K}$ and $*$ ${ }^{[9]}$ at $T=922 \mathrm{~K}$ to $979 \mathrm{~K}$.

- $98.73 \mathrm{~J}(\mathrm{~mol} \mathrm{~K})^{-1}$, respectively. Both partial enthalpies and excess entropies have minima and maxima.

The Li-Sb alloys have large negative deviations of thermodynamic properties from the ideal solution, which has been already described in References 7 through 10. Thus, it is probable that in the liquid phase the associates are forming as the result of the short-range ordering. This problem was discussed, inter alia, by Ruppersberg et al. ${ }^{[2,24]}$ and Bhatia and Thornton ${ }^{[25]}$ based on the results of the intensity $I(k)$ of the scattered
Table III. Partial Quantities of Lithium in the Liquid Phase at $T=973 \mathrm{~K}$

\begin{tabular}{lccc}
\hline$x_{\mathrm{Li}}$ & $\Delta H_{\mathrm{Li}}\left(\mathrm{J} \mathrm{mol}^{-1}\right)$ & $\Delta G_{\mathrm{Li}}^{\mathrm{E}} \cdot\left(\mathrm{J} \mathrm{mol}^{-1}\right)$ & $\Delta S_{\mathrm{Li}}^{\mathrm{E}} \cdot\left(\mathrm{J}(\mathrm{K} \mathrm{mol})^{-1}\right)$ \\
\hline 1 & 0 & 0 & 0 \\
0.9 & 131.3 & -193 & 0.06 \\
0.8 & -4030 & -3045 & -1.01 \\
0.7 & -104216 & -65766 & -39.52 \\
0.6 & -109623 & -71592 & -39.09 \\
0.5 & -105668 & -73698 & -32.86 \\
0.4 & -99602 & -75473 & -24.80 \\
0.3 & -94530 & -76927 & -18.09 \\
0.2 & -90994 & -78093 & -13.26 \\
0.1 & -88494 & -79076 & -9.68 \\
0 & -86599 & -79947 & -6.84 \\
\hline
\end{tabular}

radiation for the liquid $\mathrm{Li}-\mathrm{Pb}$ solutions. Its correlation with the fluctuation theory is shown below.

The intensity of the scattered radiation of the x-ray or neutrons is connected with the static structure factor by the relation:

$$
\begin{gathered}
I(k)=S(k) N f^{2} \\
K=[4 \pi \sin (\alpha)] / \lambda,
\end{gathered}
$$

where $I(k)$ is the intensity of the scattered radiation, $S(k)$ is the static structure factor, $N$ is the number of scattering points (for $N=1$ mole it is Avogadro's number), $f$ is the atomic scattering factor, $\alpha$ is half of the scattering angle, and $\lambda$ is the incident 
Table IV. Partial Quantities of Antimony in the Liquid Phase at $T=973 \mathrm{~K}$

\begin{tabular}{lrrc}
\hline$x_{\mathrm{Sb}}$ & $\Delta H_{\mathrm{Sb}}\left(\mathrm{J} \mathrm{mol}^{-1}\right)$ & $\Delta G_{\mathrm{Sb}}^{\mathrm{E}}\left(\mathrm{J} \mathrm{mol}^{-1}\right)$ & $\Delta S_{\mathrm{Sb}}^{\mathrm{E}}\left(\mathrm{J}(\mathrm{K} \mathrm{mol})^{-1}\right)$ \\
\hline 0 & -318657 & -222595 & -98.73 \\
0.1 & -316747 & -219386 & -100.06 \\
0.2 & -298049 & -205372 & -95.25 \\
0.3 & 2600 & -17221 & 20.34 \\
0.4 & 14233 & -5496 & 20.23 \\
0.5 & 9534 & -2882 & 12.76 \\
0.6 & 4545 & -1412 & 6.12 \\
0.7 & 1764 & -618 & 2.45 \\
0.8 & 559 & -224 & 0.81 \\
0.9 & 106 & -47 & 0.16 \\
1 & 0 & 0 & 0 \\
\hline
\end{tabular}

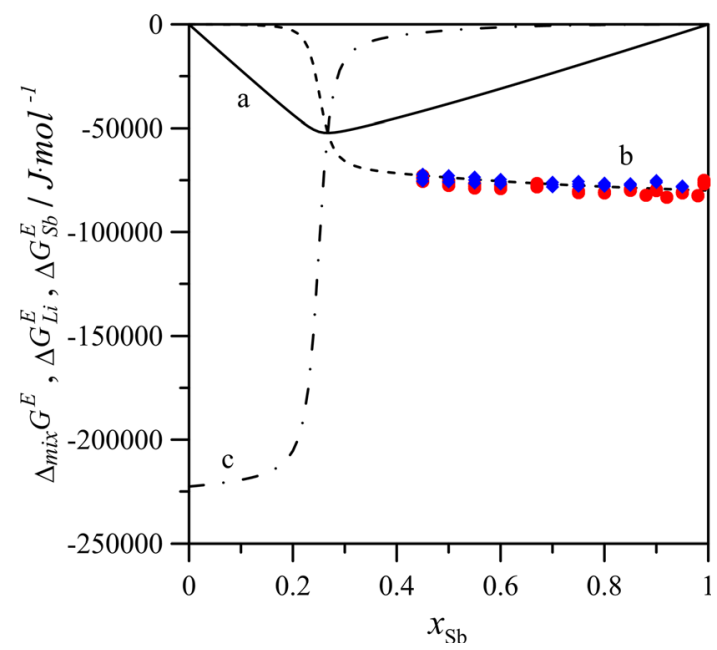

Fig. 3-Molar $\Delta_{\text {mix }} G^{\mathrm{E}}(a)$ and partial excess Gibbs energy $\left\{\Delta G_{\mathrm{Li}}^{\mathrm{E}}(b)\right.$, $\left.\Delta G_{\mathrm{Sb}}^{\mathrm{E}} \quad(c)\right\}$ of $\mathrm{Li}-\mathrm{Sb}$ solutions at $T=973 \mathrm{~K}$. Points at the temperature range $T=873 \mathrm{~K}$ to $973 \mathrm{~K}: \bullet^{[6]}$ and ${ }^{[10]}$

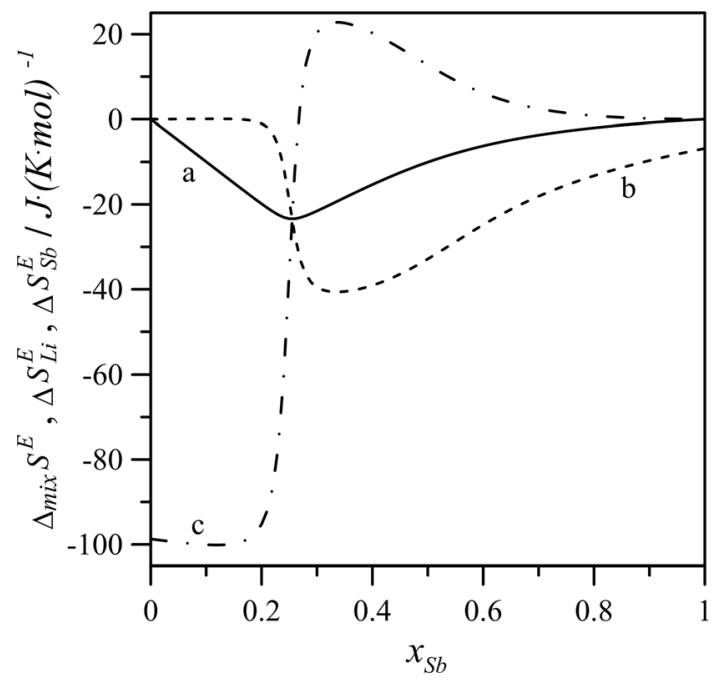

Fig. 4-Molar $\Delta_{\text {mix }} S^{\mathrm{E}}$ (a) and partial excess entropy $\left\{\Delta S_{\mathrm{Sb}}^{\mathrm{E}}\right.$ (b), $\Delta S_{\mathrm{Li}}^{\mathrm{E}}$ (c) $\}$ in the Li-Sb system at $T=973 \mathrm{~K}$.
wavelength.In turn, the static structure factor $S(k)$ is the function of the pair distribution function $g(r)$ (and vice versa), which measures the probability of finding an atom at a distance $r$ from another atom at $r=0$. For two kinds of atoms (binary solution), the probability of finding three pair of atoms, A-A, B-B and $\mathrm{A}-\mathrm{B}$, at distance $\mathrm{r}$ must be considered. Therefore, in this case there are three partial structure factors: $S_{\mathrm{AA}}(k), S_{\mathrm{BB}}(k)$ and $S_{\mathrm{AB}}(k)$ [also denoted as $a_{\mathrm{AA}}\left(a_{11}\right)$, $a_{\mathrm{BB}}\left(a_{22}\right)$ and $\left.a_{\mathrm{AB}}\left(a_{12}\right)\right]$ and three pair distribution functions: $g_{\mathrm{AA}}(r), g_{\mathrm{AB}}(r)$ and $g_{\mathrm{BB}}(r)$. As Faber and Ziman ${ }^{[26]}$ or Enderby et al. ${ }^{[27]}$ and Bhatia and Thornton $^{[25]}$ showed, the intensity of the scattered radiation $I(k)$ can be expressed in the form of a linear equation of the structure factors depending on the radial distribution functions ${ }^{[26]}$ or the structure factors depending on the fluctuation of concentration $S_{\mathrm{CC}}(k)$, the number of atoms $S_{\mathrm{NN}}(k)^{[25]}$ and the partial factor $S_{\mathrm{NC}}(k)$ being the correlation function of $S_{\mathrm{CC}}(k)$ and $S_{\mathrm{NN}}(k)$. So, $I(k)$ can be expressed by equations:

$$
\begin{aligned}
I(k)= & X_{\mathrm{A}} f_{\mathrm{A}}^{2}+X_{\mathrm{B}} f_{2}^{2}+X_{\mathrm{A}}^{2} f_{\mathrm{A}}^{2}\left(a_{\mathrm{AA}}-1\right)+X_{\mathrm{B}}^{2} f_{\mathrm{B}}^{2}\left(a_{\mathrm{BB}}-1\right) \\
& +2 X_{\mathrm{A}} X_{\mathrm{B}} f_{\mathrm{A}} f_{\mathrm{B}}\left(a_{\mathrm{AB}}-1\right) \\
I(k)= & f_{\mathrm{AB}}^{2} S_{\mathrm{NN}}(k)+\Delta f_{\mathrm{AB}}^{2} S_{\mathrm{cc}}(k)+2 f_{\mathrm{AB}} \Delta f_{\mathrm{AB}} S_{\mathrm{NC}}(k)
\end{aligned}
$$

where $f_{\mathrm{AB}}^{2}=X_{\mathrm{A}} f_{\mathrm{A}}+X_{\mathrm{B}} f_{\mathrm{B}} ; \Delta f_{\mathrm{AB}}^{2}=f_{\mathrm{A}}-f_{\mathrm{B}}$ and $X_{\mathrm{A}}, X_{\mathrm{B}}$ denote the mole fraction of $\mathrm{A}-\mathrm{B}$ alloy components and $f_{\mathrm{A}}$ and $f_{\mathrm{B}}$ are atomic scattering factors of $\mathrm{A}$ and $\mathrm{B}$ atoms.

As Bhatia and Thornton ${ }^{[25]}$ show, for the long wavelength limit, this means that for $k=0, S_{\mathrm{cc}}(0)$, $S_{\mathrm{NN}}(0)$ and $S_{\mathrm{NC}}(0)$ can be calculated directly with the thermodynamic and physical properties of the alloy according to the equations:

$$
\begin{gathered}
S_{\mathrm{CC}}(0)=\left\langle(\Delta X)^{2}\right\rangle N=R T\left[\frac{\mathrm{d}^{2} \Delta_{\mathrm{mix}} G}{\mathrm{~d} X^{2}}\right]^{-1} \\
S_{\mathrm{NN}}(0)=\frac{\left\langle(\Delta N)^{2}\right\rangle}{N}=\frac{R T \kappa_{T}+\left(\bar{V}_{\mathrm{A}}-\bar{V}_{\mathrm{B}}\right) S_{\mathrm{CC}}(0)}{V^{\prime}} \\
S_{\mathrm{NC}}(0)=\langle\Delta N \Delta X\rangle=\frac{-\left(\bar{V}_{\mathrm{A}}-\bar{V}_{\mathrm{B}}\right) S_{\mathrm{CC}}(0)}{V^{\prime}}
\end{gathered}
$$

where $\kappa_{T}$ is the isothermal compressibility, $V^{\prime}$ is the molar volume of alloys, $\bar{V}_{\mathrm{A}}, \bar{V}_{\mathrm{B}}$ are the partial molar volumes of the $\mathrm{A}$ and $\mathrm{B}$ components, respectively, $\mathrm{R}$ is the universal gas constant, $\mathrm{T}$ is temperature, $N$ is Avogadro's number, $(\Delta X)^{2}$ is the mean-square fluctuation in concentration, $(\Delta N)^{2}$ is the mean-square fluctuation in a number of particles, $\Delta N \Delta X$ is the correlation between the two fluctuations, and $\Delta_{\text {mix }} G$ is the molar Gibbs free energy change.

As the above equations show, $S_{\mathrm{CC}}(0)$ can only be calculated based on the thermodynamics of a solution. 
The discussion of $S_{\mathrm{CC}}(0)$ for the different solutions was presented, inter alia, by Ruppersberg et al. ${ }^{\left[{ }^{[2,24]}\right.}$ Bhatia and Thornton ${ }^{[25]}$ and Shing et al. ${ }^{[28]}$ The general conclusion is that for the alloys the negative deviations from the ideal, once $S_{\mathrm{CC}}(0)$ shows lower values than for the ideal solutions, and the minimum value of $S_{\mathrm{CC}}(0)$ is observed for the concentration, one of the intermetallic compounds occurred in a given system. However, for many systems characterized by the negative deviation from ideality, $S_{\mathrm{CC}}(0)$ calculated based on the available equations describing thermodynamics (excess Gibbs free energy) of liquid solutions shows an inflection, not a minimum for the composition of the intermetallic phase observed in the solid solutions. The reason for this is the use of an improper model(s) to elaborate the experimental thermodynamic data.

Continuing the discussion on the structure of alloys with high negative deviations of $\Delta_{\text {mix }} G^{\mathrm{E}}$ from the ideal solution, note that $S_{\mathrm{CC}}(0)$ can be calculated not only using the molar Gibbs energy change but also the activity and activity coefficient, applying the following relations:

$$
\begin{gathered}
S_{\mathrm{CC}}(0)=R T\left(\frac{\partial^{2} \Delta_{\text {mix }} G}{\partial X_{\mathrm{A}}^{2}}\right)^{-1}=X_{\mathrm{B}} a_{\mathrm{A}}\left(\frac{\partial a_{\mathrm{A}}}{\partial X_{\mathrm{A}}}\right)^{-1} \\
=X_{\mathrm{A}} a_{\mathrm{B}}\left(\frac{\partial a_{\mathrm{B}}}{\partial x_{\mathrm{B}}}\right)^{-1} \\
S_{\mathrm{CC}}(0)=\frac{X_{\mathrm{A}} X_{\mathrm{B}}}{X_{\mathrm{A}}\left[\frac{\mathrm{d} \ln \left(\gamma_{\mathrm{A}}\right)}{\mathrm{d} x_{\mathrm{A}}}+1\right]}=\frac{X_{\mathrm{A}} X_{\mathrm{B}}}{X_{B}\left[\frac{\mathrm{d} \ln \left(\gamma_{\mathrm{B}}\right)}{\mathrm{d} X_{\mathrm{B}}}+1\right]} \\
S_{\mathrm{CC}}(0)_{i}=X_{\mathrm{A}} X_{\mathrm{B}},
\end{gathered}
$$

where $\Delta_{\text {mix }} G$ is the mixing Gibbs energy $\left(\Delta_{\text {mix }} G=\Delta_{\text {mix }} G^{\text {id }}+\Delta_{\text {mix }} G^{\mathrm{E}}\right) ; \quad a_{\mathrm{A}(\mathrm{B})}$ and $X_{\mathrm{A}(\mathrm{B})}$ are the activities and the mole fractions of components $\mathrm{A}$ and $\mathrm{B}$ $(\mathrm{Li}$ and $\mathrm{Sb})$, respectively; $T$ is the temperature in Kelvin, $R$ is the universal gas constant, and $S_{\mathrm{CC}}(0)_{i}$ is the limit value of $S_{\mathrm{CC}}(k)$ in the case of ideal solutions.

The $S_{\mathrm{CC}}(0)$ for the real and ideal liquid solution for the $\mathrm{Li}-\mathrm{Sb}$ system is presented in Figure 5, which also shows the difference $\Delta S_{\mathrm{CC}}(0)^{[22]}$ between the ideal and real concentration factors. The latter was suggested to be more proper for the identification of the type of associate in the case of the lack of evident minimum at the $S_{\mathrm{CC}}(0)$ curve. As could be expected, the $S_{\mathrm{CC}}(0)$ dependence on the concentration of $\mathrm{Sb}$ at $1500 \mathrm{~K}$, visible in Figure 5, presents a clear minimum located almost exactly for $x_{\mathrm{Li}}=0.75\left(\mathrm{Li}_{3} \mathrm{Sb}\right)$, which in the literature is thought to be the associate's creation in the liquid phase. The presence of this associate in the liquid $\mathrm{Li}-\mathrm{Sb}$ solutions was expected because of the $\mathrm{Li}_{3} \mathrm{Sb}$ intermetallic phase in solid solutions and deep minima of thermodynamic functions analyzed above in the vicinity of composition $x_{L i}=0.75$. Consequently, the assumption of this type of associate was assumed in the elaboration of thermodynamic properties by Eqs. [3] and [5], and, in this case, the minimum at the $S_{\mathrm{CC}}(0)$ curve for $x_{\mathrm{Li}}=0.75$ must have appeared. Figure 5

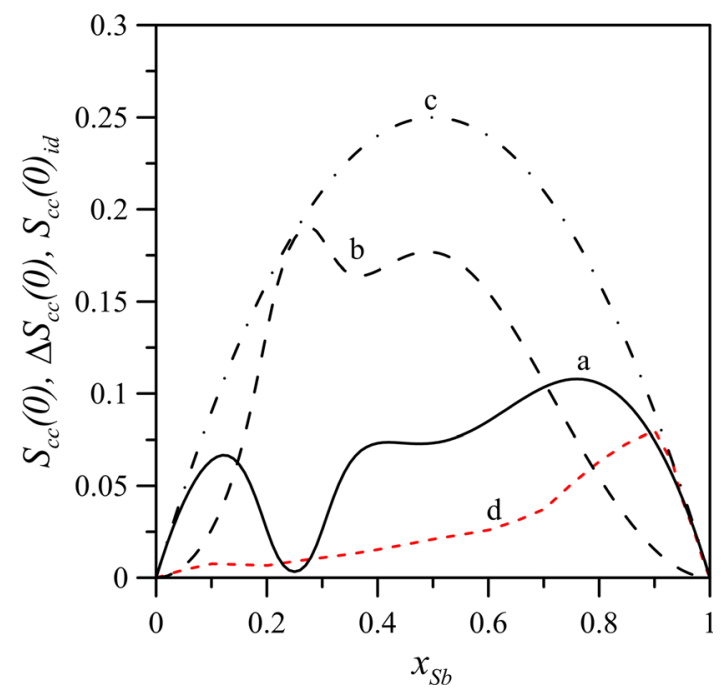

Fig. 5-Long-wavelength limit value of (concentrationconcentration) structure factor $S_{\mathrm{cc}}(0)$ (black solid line) (a), $\Delta S_{\mathrm{CC}}(0)$ (black dashed line) (b) and $S_{\mathrm{CC}}(0)_{\text {id }}(\mathrm{c})$ at $T=1500 \mathrm{~K}$, together with the $S_{\mathrm{CC}}(0)$ calculated by Ref. [10] at $1500 \mathrm{~K}$ by the association model.

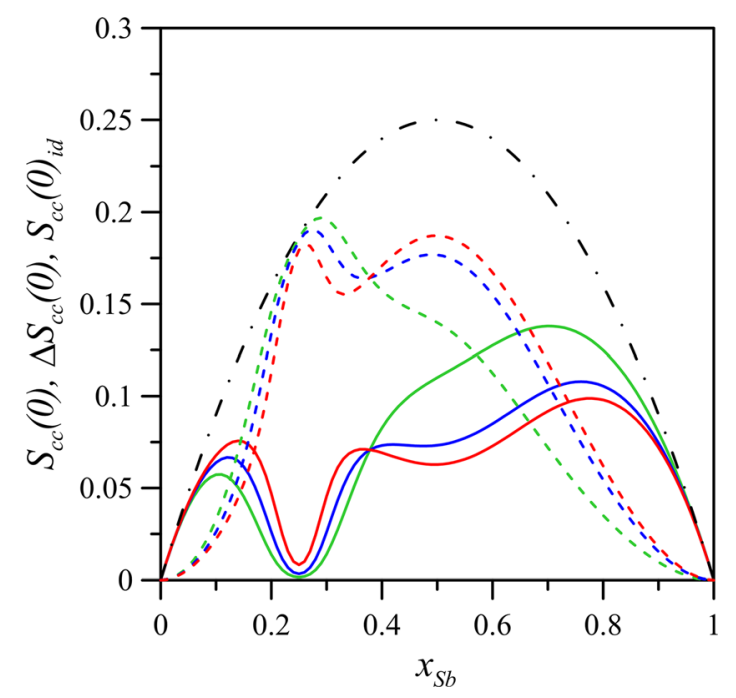

Fig. 6- Long-wavelength limit value of (concentrationconcentration) structure factor $S_{\mathrm{CC}}(0)$ calculated at $1000 \mathrm{~K}, 1500 \mathrm{~K}$ and $2000 \mathrm{~K}$ (green, blue and red solid lines, respectively), $\Delta S_{\mathrm{CC}}(0)$ (green, blue and red dashed lines, respectively) and $S_{\mathrm{CC}}(0)_{\mathrm{id}}$ (dashed-dotted line) (Color figure online).

shows that the $\Delta S_{\mathrm{CC}}(0)$ maximum is for the alloy of $x_{\mathrm{Li}}=0.73$ and not for $\mathrm{Li}_{3} \mathrm{Sb}$. The second weak minimum is for $x_{\mathrm{Li}}=0.5$, which corresponds to $\mathrm{LiSb}$ associate. However, the minimum value for $\mathrm{Li}_{3} \mathrm{Sb}$ is much lower than that for LiSb.

The influence of temperature on the $S_{\mathrm{CC}}(0)$ and $\Delta S_{\mathrm{CC}}(0)$ is shown in Figure 6 . As is clearly seen, the increase of temperature changes the shape of both functions and the dominant influence of $\mathrm{Li}_{3} \mathrm{Sb}$ at $1000 \mathrm{~K}$ is lowered at $1500 \mathrm{~K}$ and $2000 \mathrm{~K}$; a greater influence of LiSb is also observed. As a result, the lower value of $S_{\mathrm{CC}}(0)$ of the LiSb associate and higher value of 
$S_{\mathrm{CC}}(0)$ of the $\mathrm{Li}_{3} \mathrm{Sb}$ associate is observed at $2000 \mathrm{~K}$ compared to that at $1000 \mathrm{~K}$ and $1500 \mathrm{~K}$. This means that the amount of LiSb associates increases and of $\mathrm{Li}_{3} \mathrm{Sb}$ associates decreases with increasing temperature. A similar conclusion can be made by analyzing the $\Delta S_{\mathrm{CC}}(0)$.

The second function, which suggests the existence of associates in the liquid phase, is the excess stability function $(E S)$ proposed by Darken. ${ }^{[29]}$ This function is directly related to the partial structure factor $S_{\mathrm{CC}}(0)$ and is defined as the second derivative of excess Gibbs energy $\left(\Delta_{\text {mix }} G^{\mathrm{E}}\right)$ of the concentration of the component $\left(x_{i}\right)$ :

$$
E S=\frac{\mathrm{d}^{2}\left(\Delta_{\mathrm{mix}} G^{\mathrm{E}}\right)}{\mathrm{d} x_{i}^{2}}=R T\left[\frac{1}{S_{\mathrm{cc}}(0)}-\frac{1}{S_{\mathrm{cc}}(0)_{\mathrm{id}}}\right]
$$

Substituting the $\Delta_{\text {mix }} G^{E}$ as a sum of partial excess Gibbs energy of components $\left(\Delta \bar{G}_{i}^{\mathrm{E}}\right)$ multiplied by its mole fractions $\left(x_{i}\right)$ and performing appropriate mathematical transformations, the following equation is reached:

$$
E S=\frac{R \Delta T}{1-x_{i}} \cdot\left(\frac{\mathrm{d} \ln \gamma_{i}}{\mathrm{~d} x_{i}}\right),
$$

where $\gamma_{i}$ is the activity coefficient of component $i$.

The $E S$ function usually presents the maximum near or at the concentration of the high-temperature intermetallic phase. When the above-mentioned maximum exists in the studied system, the existence of associates in the liquid phase is highly probable. The calculated ES function for the $\mathrm{Li}-\mathrm{Sb}$ system at three different temperatures $(1000 \mathrm{~K}$, $1500 \mathrm{~K}$ and $2000 \mathrm{~K}$ ) is presented in Figure 7. A clear maximum exists for $x_{\mathrm{Li}}=0.75$, which suggests the occurrence of associates of the chemical formula $\mathrm{Li}_{3} \mathrm{Sb}$. A slight maximum is also noticeable for $x_{\mathrm{Li}}=0.50$ (LiSb). Moreover, the influence of temperature on the structure of $\mathrm{Li}-\mathrm{Sb}$ liquid alloys is obvious, and the same conclusions can be drawn as in the case of $S_{\mathrm{CC}}(0)$.

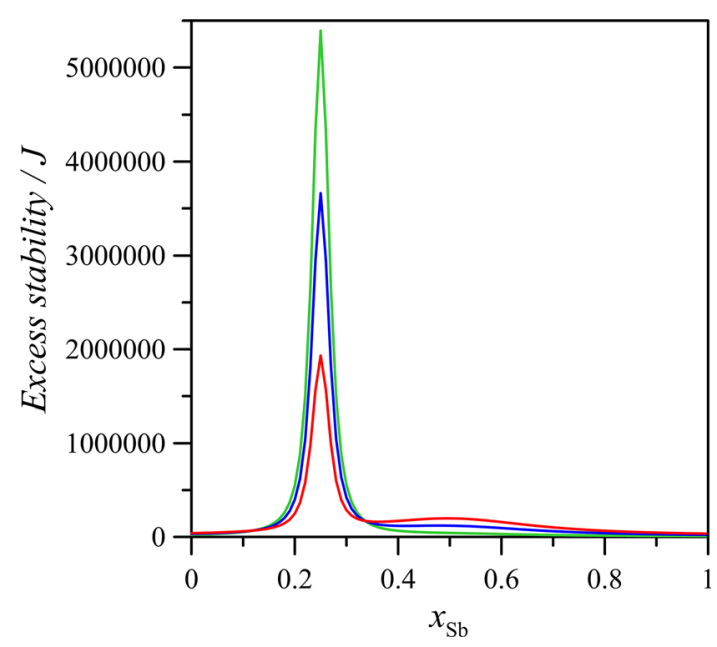

Fig. 7-Excess stability (ES) function of liquid Li-Sb alloys at $1000 \mathrm{~K}, 1500 \mathrm{~K}$ and $2000 \mathrm{~K}$ (green, blue and red lines, respectively) (Color figure online).
The next parameters indicating the occurrence of the associate(s) in the liquid phase is the Warren-Cowley short-range-order parameter $(\operatorname{SRO}(\alpha)){ }^{[28,30-33]}$ Its values vary from 1 to -1 . If it is negative, this means that in the liquid solutions the interaction between different atoms is much stronger than between the same atoms and the associates can be formed. If the value of $\operatorname{SRO}(\alpha)$ is positive, the interaction is stronger between the same type of atoms, so the formation of associates with different atoms is impossible, and such solutions will tend to segregate.

The calculation of the $\operatorname{SRO}(\alpha)$ was done using the following formula:

$$
\alpha=\frac{Q-1}{1+Q(z-1)},
$$

where:

$$
Q=\frac{S_{\mathrm{cc}}(0)}{x_{1} x_{2}}=\frac{S_{\mathrm{cc}}(0)}{S_{\mathrm{cc}}(0)_{\mathrm{id}}},
$$

where $x_{1}, x_{2}$ is the molar fraction of the binary system components ( $\mathrm{Li}, \mathrm{Sb}$ ), and $z$ is the coordination number of liquid solutions. Based on the calculation presented in, ${ }^{[33]}$ the $z$ equals 10 for the liquids.

The values of the chemical short-range-order parameter $\operatorname{SRO}(\alpha)$ for liquid Li-Sb solutions are presented in Figures 8(a) and (b). They are negative in the entire concentration range, with the strong, clear minimum at $x_{\mathrm{Li}}=0.75$. This decrease near the composition of the high-temperature intermetallic phase confirms that, in the liquid phase of $\mathrm{Li}-\mathrm{Sb}$ system, the $\mathrm{Li}_{3} \mathrm{Sb}$ associate exists. For comparison, Figure 8(a) also shows the values obtained by Trybula et al. ${ }^{[10]}$ from the elaboration of experimental data by the Sommer's association model. ${ }^{[22]}$ The great differences observed are the consequence of the interpretation of the experimental data. The development of $\operatorname{SRO}(\alpha)$ with the temperature increase is presented in Figure 8(b). Considering that stronger interaction of atoms should be manifested by the lower values of $\operatorname{SRO}(\alpha)$, we can state that the higher the temperature, the worse the interaction between components of $\mathrm{Li}_{3} \mathrm{Sb}$ is and the more $\mathrm{LiSb}$ associates exist in the liquid solution. It is because with the increase of temperature the solutions lead to the ideal ones.

Finishing the discussion on the structure of liquid Li-Sb solutions, the authors would like to draw attention to the property of the $S$ parameter in the equation of $\operatorname{SRO}(\alpha)$ (Eq. [28]), used also by Reference 34 to model the diffusion coefficients (the inverse of the $Q$ parameter is used in the calculation of viscosity and diffusion coefficients by Singh and Sommer ${ }^{[34]}$, which is the quotient of the real $S_{\mathrm{CC}}(0)$ to $S_{\mathrm{CC}}(0)_{\text {id }}$ of ideal solutions. Figure 9 shows the same three temperatures $(1000 \mathrm{~K}$, $1500 \mathrm{~K}, 2000 \mathrm{~K}$ ) as presented above for the structure factors.

$Q$ is also exactly characterized by the deep minimum for the proper composition of $\mathrm{Li}_{3} \mathrm{Sb}$. Its values change from 0 to 1 for the systems with a negative deviation from the ideal, and those with positive ones have values $>1$. Hence, it also can be a kind of indicator of the 

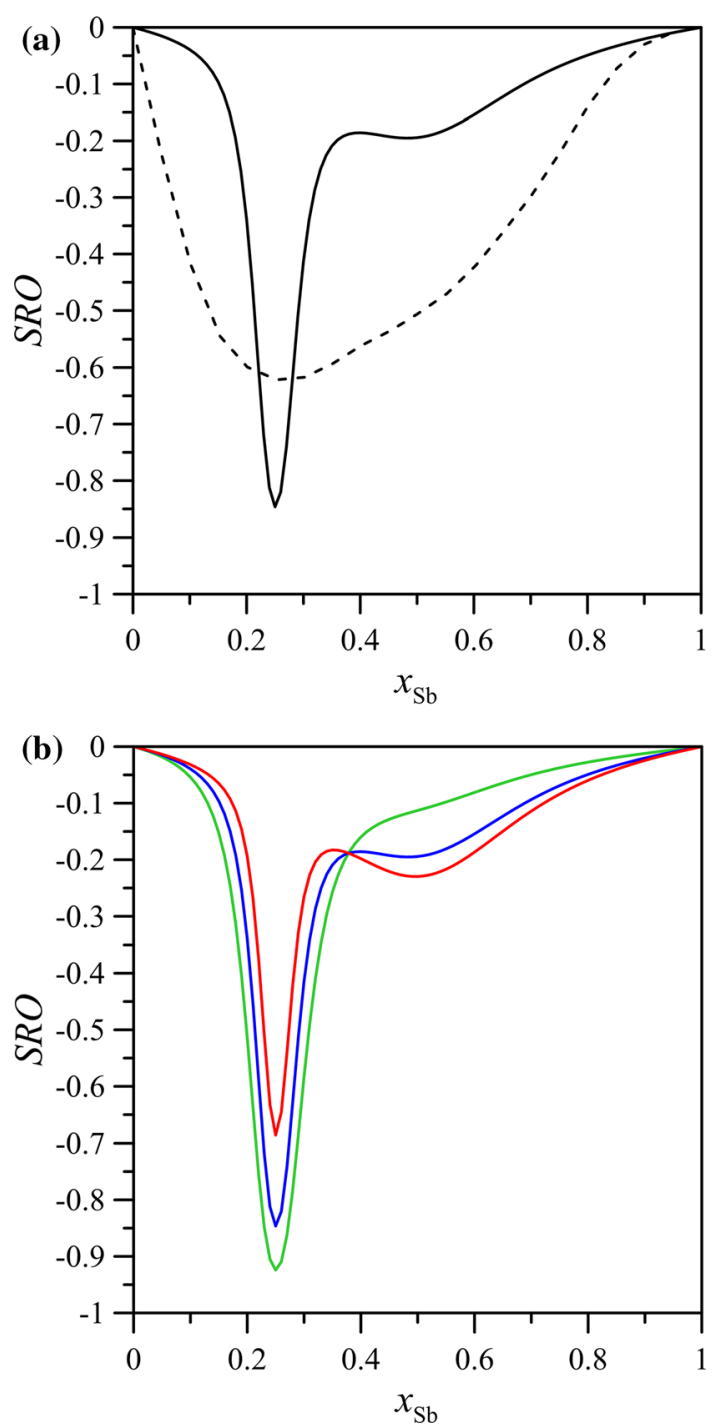

Fig. 8- (a) Chemical short-range-order parameter $(\operatorname{SRO}(\alpha))$ for liquid Li-Sb alloys at $1500 \mathrm{~K}$ (this study: solid black line) together with the $\operatorname{SRO}(\alpha)$ calculated by Ref. 10 using the association model (dashed line); $(b)$ comparison of $S R O(\alpha)$ at $1000 \mathrm{~K}, 1500 \mathrm{~K}$ and $2000 \mathrm{~K}$ obtained by the QAM model.

existence of associates in liquid solutions. One can also notice that $Q$ is independent of the coordination number $z$ as $\alpha$, and it is calculated directly only from the thermodynamic properties of liquid solutions similar to $S_{\mathrm{CC}}(0)$ and ES. The conclusions that can be reached from the analysis of $Q$ at different temperatures are the same as in the case of $S_{\mathrm{CC}}(0)$, ES and $\operatorname{SRO}(\alpha)$.

The changes in the enthalpy of the mixing of liquid Li-Sb alloys calculated using the QAM model at $1000 \mathrm{~K}$ are illustrated in Figure 10(a) and compared with the experimental ${ }^{[7,9]}$ and modeled data presented by $\mathrm{Li}$ et $a l .{ }^{[9]}$ via an associate-based model at $1000 \mathrm{~K}$ and Trybula et al. ${ }^{[10]}$ by associate-based and sub-regular models, both computed at $1000 \mathrm{~K}$. There is a very good correlation between the values of the enthalpy of mixing obtained experimentally and those obtained by the proposed QAM model for Li-Sb alloys. This is contrary

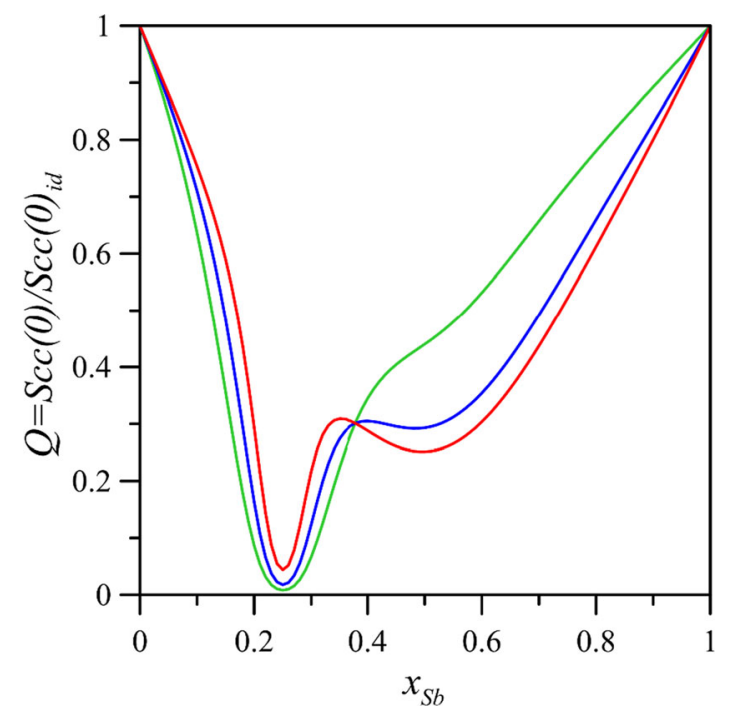

Fig. 9-Graphical representation of the $S$ parameter from the equation of $\operatorname{SRO}(\alpha)$ at $1000 \mathrm{~K}$ (green line), $1500 \mathrm{~K}$ (blue line) and $2000 \mathrm{~K}$ (red line) (Color figure online).

to the models used by Li et al. ${ }^{[9]}$ and Trybula et al. ${ }^{[10]}$ where the experimental values differ more significantly from those obtained through the experimental methods. It is especially noticeable for alloys rich in $\mathrm{Li}\left(0.9<x_{\mathrm{Li}}<\right.$ 0.8 ). Moreover, the predicted $\Delta_{\text {mix }} H$ by References 9 and 10 is less negative compared to that presented in this work model and in Reference 12. The shape of $\Delta_{\text {mix }} H$ of all visible thermodynamic models is generally asymmetrical. However, the minimum of this function differs from about $x_{\mathrm{Li}}=0.68$ for both models presented by Trybula et al. ${ }^{[10]}$ (blue and red lines) to $x_{\mathrm{Li}}=0.70$ for $\mathrm{Li}$ et al. ${ }^{[9]}$ (green line) up to $x_{\mathrm{Li}}=0.75$ for the QAM model and $^{[12]}$ (black line).

The comparison of the partial enthalpy change of $\mathrm{Li}$ and $\mathrm{Sb}$ is shown in Figure 10(b), where the experimental results of References 6,7 and 9, are drawn along with those calculated using the QAM model presented in this work and the association model by Reference 12 used in the calculations of the $\mathrm{Li}-\mathrm{Sb}$ phase diagram. The experimental values ${ }^{[9]}$ of partial enthalpy of $\mathrm{Li}$ and $\mathrm{Sb}$ agree very well with those obtained by the QAM model. Comparing the modeled data with the experimental values, as was done by Zhang et al. ${ }^{[12]}$ shows better compatibility of $\Delta H_{\mathrm{Li}}$ values and somewhat worse agreement of $\Delta H_{\mathrm{Sb}}$. The difference between the measured and calculated values of partial enthalpy of $\mathrm{Sb}$ is because literature data were probably measured in the solid-liquid range. ${ }^{[7,9]}$

In Figures 11 and 12 the partial Gibbs energy change of $\mathrm{Li}$ and $\mathrm{Sb}$ is compared with those from Reference 10 at three temperatures. In Figure 13, the same functions are shown only at $1000 \mathrm{~K}$ and compared with the experimental data. ${ }^{[6,7]}$ The observed differences between experimental and modeled values at $1000 \mathrm{~K}$ (Figure 13) are the lowest for the QAM model presented in this work (maximum $2.5 \mathrm{~kJ} \mathrm{~mol}^{-1}$ ), and the highest is for the sub-regular model (about $50 \mathrm{~kJ} \mathrm{~mol}^{-1}$ ). Maximum deviations of the values calculated by the association 

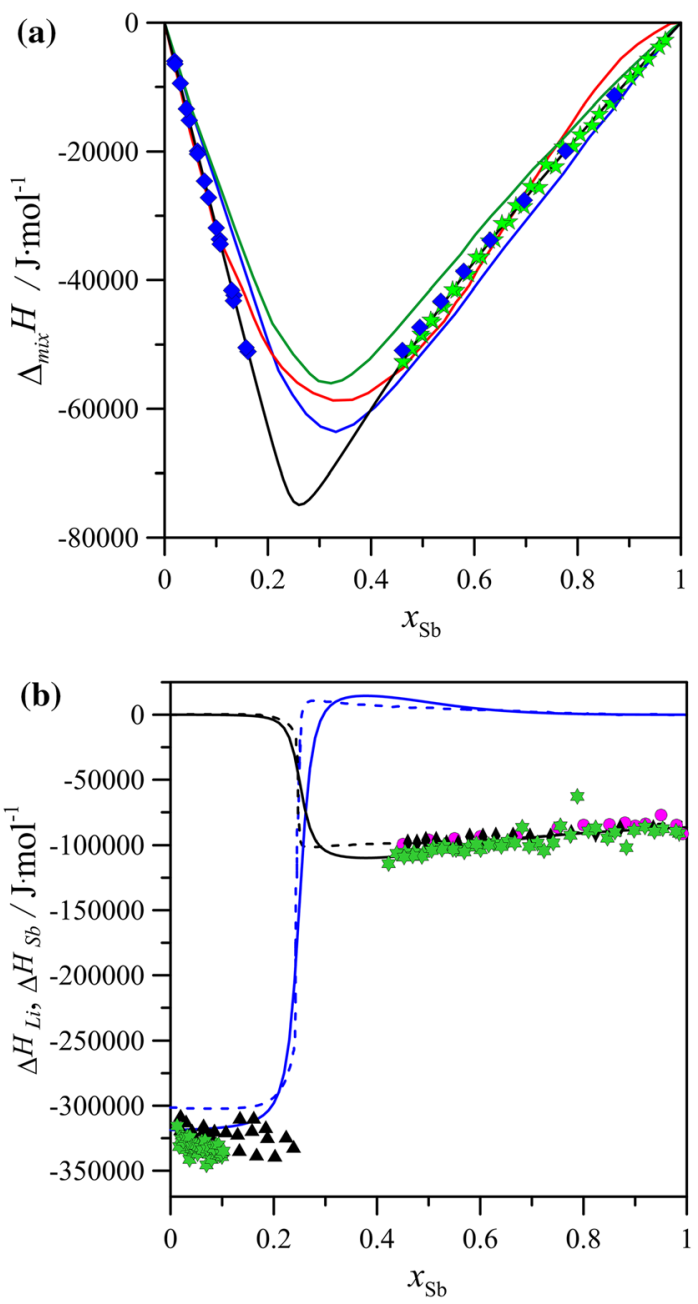

Fig. 10- (a) Changes of enthalpy of mixing of liquid Li-Sb alloys at $1000 \mathrm{~K}$, calculated in this work by the QAM model (black line), together with literature data: association model of Li et al. (green line) ${ }^{[9]}$; sub-regular model of Trybula et al. (red line) ${ }^{[10]}$; association model of Trybula et al. (blue line). ${ }^{[10]}$ (b) Partial enthalpy of Li and Sb calculated at $973 \mathrm{~K}$ by a new QAM model $\left(\Delta H_{\mathrm{Li}}\right.$ black solid line, $\Delta H_{\mathrm{Sb}}$ blue solid line) together with the literature data: association model presented by Zhang et al. ${ }^{[12]}\left(\Delta H_{\mathrm{Li}}\right.$ : black dashed line, $\Delta H_{\mathrm{Sb}}$ : blue dashed line) and experimental data: $\boldsymbol{\otimes}^{[6]} ; \bullet^{[7]}$ at $T=922 \mathrm{~K}$, $\boldsymbol{\Delta}^{[7]}$ at $T=820 \mathrm{~K}$ to $1024 \mathrm{~K}, \boldsymbol{\square}^{[9]}$ at $T=929 \mathrm{~K}$ to $1080 \mathrm{~K}$ (Color figure online).

mode ${ }^{[10]}$ and from the experimental results are about $10 \mathrm{~kJ} \mathrm{~mol}^{-1}$ for the solutions from the concentration range between $x_{\mathrm{Sb}} \cong 0.6$ to 0.8 . Data obtained by Reference 9 for $x_{\mathrm{Sb}} \cong 0.4$ to 1 and 0 to 0.15 are close to those gained from QAM model and experiment. ${ }^{[6,7]}$ Between $x_{\mathrm{Sb}} \cong 0.15$ to 0.4 the courses of lines are completely different. Analyzing the shape of functions of the partial molar Gibbs energy of Li and Sb calculated applying the QAM and association model ${ }^{[10]}$ shows that, first, their inflection points are located in different concentrations. In the case of the QAM model, the inflection is almost exact for $x_{\mathrm{Sb}}=0.25$, independent of temperature, and for Reference 10 the inflection is for $x_{\mathrm{Sb}} \cong 0.85$. The shapes of the partial molar Gibbs energy of $\mathrm{Li}$ and $\mathrm{Sb}$ are also different.

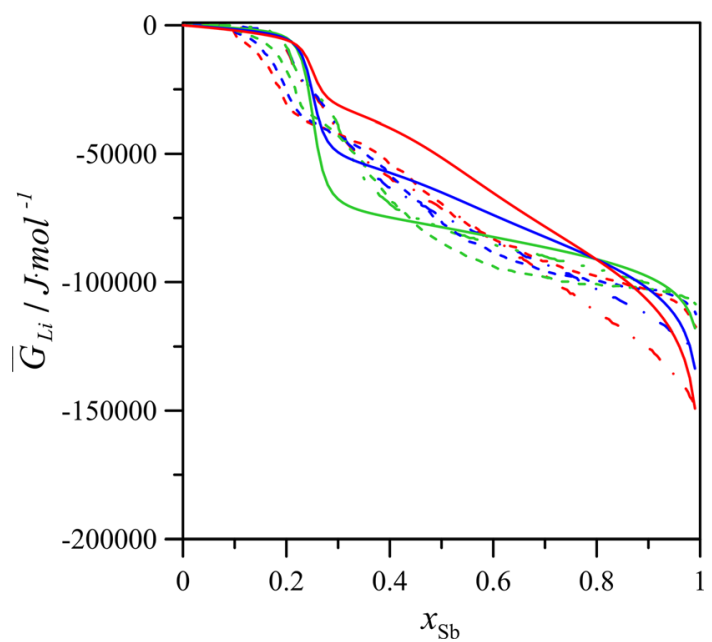

Fig. 11-Partial molar Gibbs energy of Li calculated at $1000 \mathrm{~K}$, $1500 \mathrm{~K}$ and $2000 \mathrm{~K}$; solid lines present data obtained using the QAM model (green line for $1000 \mathrm{~K}$, blue line for $1500 \mathrm{~K}$ and red line for $2000 \mathrm{~K}$ ), dashed-dotted lines present results computed using the association model from Ref. [9] (green for $1000 \mathrm{~K}$, blue for $1500 \mathrm{~K}$ and red for $2000 \mathrm{~K}$ ), and dashed lines show values calculated applying the association model computed by Ref. [10] (green for $1000 \mathrm{~K}$, blue for $1500 \mathrm{~K}$ and red for $2000 \mathrm{~K}$ ) (Color figure online).

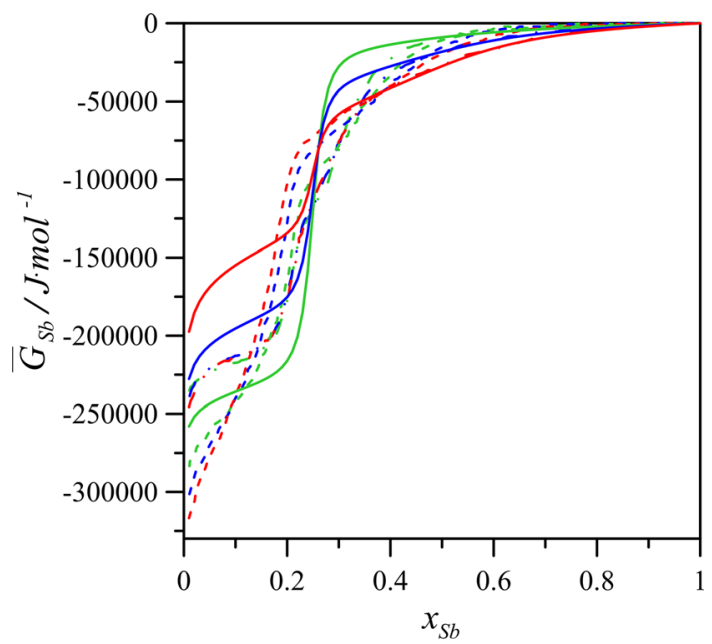

Fig. 12-Partial molar Gibbs energy of Sb calculated at 1000, 1500 and $2000 \mathrm{~K}$; solid lines present QAM model parameters (green line for $1000 \mathrm{~K}$, blue line for $1500 \mathrm{~K}$ and red line for $2000 \mathrm{~K}$ ); dashed-dotted lines present association model parameters from Ref. [9] (green for $1000 \mathrm{~K}$, blue for $1500 \mathrm{~K}$ and red for $2000 \mathrm{~K}$ ), and dashed lines show association model parameters computed by Ref. [10] (green for $1000 \mathrm{~K}$, blue for $1500 \mathrm{~K}$ and red for $2000 \mathrm{~K}$ ) (Color figure online).

\section{CONCLUSIONS}

Based on the newest available thermodynamic property data on the Li-Sb system with strong negative deviations from ideal solutions, a description of the integral molar and partial quantities such as mixing enthalpies, molar excess Gibbs energy and molar excess entropy was proposed by means of a qualitative associate model.

The calculated integral molar mixing enthalpies agree very well with the available experimental data. Moreover, the elaborated partial excess Gibbs energies are in 


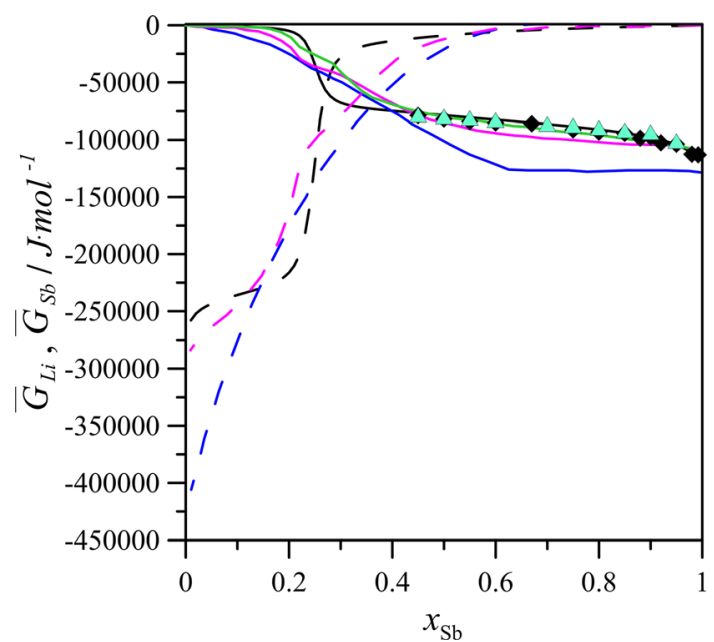

Fig. 13-Partial molar Gibbs energy of $\mathrm{Li}$ (solid lines) and $\mathrm{Sb}$ (dashed lines) calculated at $1000 \mathrm{~K}$; the QAM model parameters (black solid line for $\bar{G}_{\mathrm{Li}}$, black dashed line for $\bar{G}_{\mathrm{Sb}}$ ), parameters modeled by Ref. [9] (green solid line for $\bar{G}_{\mathrm{Li}}$ ); sub-regular model parameters from Ref. [10] (blue solid line for $\bar{G}_{\mathrm{Li}}$, blue dashed line for $\bar{G}_{\mathrm{Sb}}$ ); association model parameters from Ref. [10] (pink solid line for $\bar{G}_{\mathrm{Li}}$, pink dashed line for $\bar{G}_{\mathrm{Sb}}$ ), together with experimental data for $923 \mathrm{~K}$ : diamonds ${ }^{[6]}$ and triangles ${ }^{[7]}$ (Color figure online).

a good agreement with those experimentally measured and show the sharp increase (decrease) near to the composition of the $\mathrm{Li}_{3} \mathrm{Sb}$ compound.

The two microscopic functions $S_{\mathrm{CC}}(0)$, and $\operatorname{SRO}(\alpha)$, together with the excess stability function $(E S)$, obtained in this work, present a clear maximum and/or minimum located almost exactly at the composition proper for the intermetallic phase of higher melting temperature from the Li-Sb system. These facts suggest the prevalence of $\mathrm{Li}_{3} \mathrm{Sb}$ associates in the liquid phase, at least near the melting points of alloys. Moreover, the above-mentioned functions also present extrema (minimum or maximum) for $x_{\mathrm{Li}}=0.50$ at higher temperatures, which suggests the existence of a second $\mathrm{LiSb}$ associate in a liquid $\mathrm{Li}-\mathrm{Sb}$ solution. Additionally, the analysis of microscopic functions for different temperatures shows that the higher the temperature is, the higher the values of $S_{\mathrm{CC}}(0), \operatorname{SRO}(\alpha)$ and $Q$ and the lower the $E S$ for the concentration near $\mathrm{Li}_{3} \mathrm{Sb}$. This suggests that the stability of $\mathrm{Li}_{3} \mathrm{Sb}$ associates decreases with increasing temperature. The reverse trend is observed for the LiSb associate.

\section{CONFLICT OF INTEREST}

There are no conflicts to declare.

\section{OPEN ACCESS}

This article is licensed under a Creative Commons Attribution 4.0 International License, which permits use, sharing, adaptation, distribution and reproduction in any medium or format, as long as you give appropriate credit to the original author(s) and the source, provide a link to the Creative Commons licence, and indicate if changes were made. The images or other third party material in this article are included in the article's Creative Commons licence, unless indicated otherwise in a credit line to the material. If material is not included in the article's Creative Commons licence and your intended use is not permitted by statutory regulation or exceeds the permitted use, you will need to obtain permission directly from the copyright holder. To view a copy of this licence, visit http://creativecommons.org/licenses/by/4.0/.

\section{REFERENCES}

1. W.-J. Zhang: J. Power Sources, 2011, vol. 196, pp. 13-24.

2. C.-M. Park, J.-H. Kim, H. Kim, and H.-J. Sohn: Chem. Soc. Rev., 2010, vol. 39, pp. 3115-41.

3. C. Julien and Z. Stoynov: Materials for Lithium-Ion Batteries, Springer, Berlin, 2000.

4. D.J. Bradwell, H. Kim, A.H.C. Sirk, and D.R. Sadoway: J. Am. Chem. Soc., 2012, vol. 134, pp. 1895-97.

5. K. Wang, K. Jiang, B. Chung, T. Ouchi, P.J. Burke, D.A. Boysen, D.J. Bradwell, H. Kim, U. Muecke, and D.R. Sadoway: Nature, 2014, vol. 514, pp. 348-50.

6. M.M. Kane, J.M. Newhouse, and D.R. Sadoway: J. Electrochem. Soc., 2015, vol. 162, pp. A421-25.

7. S. Terlicka, A. Debski, and P. Fima: J. Alloys Compd., 2016, vol. 673, pp. 272-77.

8. A. Beutl, D. Cupid, and H. Flandorfer: J. Alloys Compd., 2017, vol. 695, pp. 1052-60.

9. D. Li, A. Beutl, H. Flandorfer, and D.M. Cupid: J. Alloys Compd., 2017, vol. 701, pp. 186-99.

10. M.E. Trybula, S. Terlicka, and P. Fima: J. Chem. Thermodyn., 2019, vol. 128, pp. 134-40.

11. J. Sangster and A.D. Pelton: J. Phase Equilibria, 1993, vol. 14, pp. $514-17$.

12. F. Zhang, S. Liu, J. Wang, Y. Du, and L. Sun: CALPHAD, 2017, vol. 57, pp. 28-36.

13. B. Predel and G. Oehme: Z. Metalkd., 1979, vol. 70, pp. 450-53.

14. S. Terlicka, A. Dębski, and W. Gạsior: J. Mol. Liq., 2018, vol. 249, pp. 66-72.

15. W. Gąsior and Z. Moser: J. Nucl. Mater., 2001, vol. 294, pp. 77-83.

16. B. Predel and G. Oehme: Z. Metallkd., 1979, vol. 70, pp. 450-53.

17. Z. Moser, W. Gasior, F. Sommer, G. Schwitzgebel, and B. Predel: Metall. Mater. Trans. B, 1986, vol. 17B, pp. 791-95.

18. M.L. Saboungi, J. Marr, and M. Blander: J. Chem. Phys., 1978, vol. 68, pp. 1375-84.

19. W. Gąsior, M. Zabrocki, and A. Dębski: J. Mol. Liq., 2018, vol. 249, pp. 1107-12.

20. W. Gạsior: PhD thesis, Kraków, 1991.

21. O. Redlich and A.T. Kister: Ind. Eng. Chem., 1948, vol. 40, pp. 345-48.

22. F. Sommer: Z. Metallkd., 1982, vol. 73, pp. 77-86.

23. H. Ruppersberg and H. Egger: J. Chem. Phys., 1975, vol. 63, pp. 4095-4103.

24. H. Ruppersberg and W. Schirmacher: J. Phys. F, 1984, vol. 14, pp. 2787-95.

25. A.B. Bhatia and D.E. Thornton: Phys. Rev. B, 1970, vol. 2, pp. 3004-12.

26. T.E. Faber and J.M. Ziman: Philos. Mag., 1965, vol. 11, pp. 153-73

27. J.E. Enderby, D.N. North, and P.A. Egelstaff: Philos. Mag., 1966, vol. 14, pp. 961-70.

28. R.N. Singh, D.K. Pandey, S. Sinha, N.R. Mitra, and P.L. Srivastava: Physica $B+C, 1987$, vol. 145, pp. 358-64.

29. L.S. Darken: Trans. Met. Soc. AIME, 1967, vol. 239, pp. 80-83.

30. B.E. Warren: X-ray Diffraction, Addison Wesley, Reading, 1969. 
31. J.M. Cowley: Phys. Rev., 1950, vol. 77, pp. 669-75.

32. J.M. Cowley: Diffraction Physics, Elsevier, New York, 1975.

33. M. Trybuła: Thermodynamic, Structural and Thermophysical Properties of Liquid Al-Li-Zn Alloys, Institute of Metallurgy and Materials Science, Kraków, 2015.
34. R.N. Singh and F. Sommer: Phys. Chem. Liq., 1998, vol. 36, pp. 17-28.

Publisher's Note Springer Nature remains neutral with regard to jurisdictional claims in published maps and institutional affiliations. 